\title{
WINST- EN VERMOGENSBEPALING IN NEDERLAND ELCK WAT WILS?*
}

\author{
door Prof. Dr. R. Slot
}

\section{Normering}

Een cruciale bepaling in de wettelijke regeling betreffende de jaarrekening is het bekende BW-artikel 2:311 lid 1, inhoudend dat de grondslagen van de winst-en vermogensbepaling moeten voldoen aan normen die ,in het maatschappelijk verkeer als aanvaardbaar worden beschouwd". Dat dit artikel - overeenkomstig het ontwerp van de Commissie-Verdam - niet bepaalde maatstaven voorschrijft, werd in de Memorie van Toelichting bij de desbetreffende wet onder andere ge. motiveerd met er op te wijzen dat „de wetenschappelijke beoefening van de be. drijfseconomie nog te zeer in beweging is om in de wet een bepaalde methode vast te leggen".") Wat dit laatste betreft, inderdaad is door verscheidene bedrijfs. economen juist in de jaren voorafgaande aan de nieuwe wettelijke regeling be. treffende de jaarrekening (1970) met klem naar voren gebracht, dat één bepaald, universeel toepasbaar winstbegrip niet bestaat. Zo werd gesteld dat een ,,absoluut winstbegrip" een "onbereikbaar ideaal” is (Pruyt), dat ook de vervangingswaarde leer geen aanspraak kan maken op algemene geldigheid (Van Straaten), dat geen enkele winstbepalingsmethode als objectief juist kan worden beschouwd (Bur. gert $)^{2}$.)

Liet de wetgever aldus ten aanzien van de grondslagen der winst. en vermo. gensbepaling een grote mate van vrijheid bestaan, tegelijk nodigde hij bedrijfs. leven en accountants uit tot een nader onderzoek hieromtrent. Het in 1971 daar. uit voortgekomen Tripartiete Overleg (TO) kwam na vijf jaar . en wel in december 1976 - tot een voorontwerp (aflevering nr. 5), waarin het een voorkeur uitšprak voor balanswaardering en winstbepaling op basis van de actuele waarde (althans indien de grondslag van de historische kosten tot uitkomsten leidt die daarvan in belangrijke mate afwijken). Als aanvulling hierop zou dan informatie op basis van de historische kosten moeten worden gegeven, en wel in de toelichting. On. der de actuele waarde werd in het algemeen verstaan de laagste van vervangings. waarde en opbrengstwaarde.

Tot een „Beschouwing” over dit onderwerp kwam het in februari 1979: in Supplement 5 , aflevering 3 , werd als standpunt geformuleerd, dat de jaarrekening vermogen en resultaat moet weergeven zowel op basis van de historische kosten als op die van de actuele waarde ${ }^{3}$ ). Er werd nu dus niet slechts een voorkeur uit. gesproken, zoals in het Voorontwerp, maar een norm gesteld. Met een aanvul. lende berekening volgens actuele waarden mag evenwel worden volstaan; de officiële balans en resultatenrekening kunnen op de historische kosten blijven be. rusten.

\footnotetext{
Dit artikel is een bewerkte versie van een voordracht, gehouden op een seminar van Euroforum op 26 november 1979 Memorie van Toelichting bij de Wet op de Jaartekening van ondernemingen, blz. 13.

Zie hierover verder R. Slot en R. M. Vijn, De ontwikkeling van het winstbegrip (1979), blz. $111 / \mathrm{m} 15$.

Indien het verstrekken van deze informatie grote praktische bezwaren met zich brengt, kan met het verschaffen van een globaal inzicht worden volstaan (t.a.p. III a9.4, par. 16).
} 
Voor de bepaling van het resultaat op basis van de actuele waarde achtte het TO in deze Beschouwing drie methoden aanvaardbaar: het lifostelsel, het ijzerenvoorraad. en het vervangingswaardestelsel ${ }^{4}$ ); geen aanleiding werd gevonden, ,, in te gaan op methoden van winst- en vermogensbepaling in voor koopkrachtfluc. tuaties gecorrigeerde geldeenheden"5). Bij het vervangingswaardestelsel werd vermeld, dat de waardeverandering van de normale voorraad ten gunste of ten laste van de rekening Herwaardering (of Prijsverschillen) komt, ,in het algemeen onder aftrek van de belastinglatentie". ${ }^{6}$ )

De uitspraken van het TO hebben slechts het karakter van "meningsuitingen" of ,vingerwijzingen”, zeggen de accountants Bindenga resp. Burggraaff.') Positiever is J. van Slooten, de president van de Ondernemingskamer; hij merkte de TO. beschouwingen aan als "gezaghebbende oordelen"8). Nu mogen deze beschou wingen inderdaad een ,belangrijke, gezaghebbende kenbron” zijn $\left.{ }^{9}\right)$ formeel hebben zij (nog?) geen bindende kracht. Het staat de ondernemer vrij, in zijn jaarrekening af te wijken van de richtlijnen van het TO, die overigens mede door zijn eigen representanten zijn opgesteld. Van deze mogelijkheid maakt het bedrijfs. leven te onzent in ruime mate gebruik, zoals wij hieronder zullen toelichten. Ook de Ondernemingskamer vindt het daarbij vooralsnog niet op zijn weg: in de zaak Sobi-KSH althans deed deze kamer op 16 maart 1978 de uitspraak dat ook het stelsel van de historische kostprijs voor wat de voorraadwaardering betreft , in het maatschappelijk verkeer als aanvaardbaar wordt beschouwd en dat bij juiste toe. passing en toelichting daarvan de jaarrekening in het algemeen het door de wet vereiste inzicht geeft".

Vermelden wij nog dat ook van de zijde van de Europese Gemeenschap en van de International Accounting Standard Committee tot nu toe geen enkel voor. schrift is gekomen dat toepassing van actuele waarden in de jaarrekening ver. plicht stelt.

\section{Praktijk}

De praktijk van de jaarverslaggeving is in ons land reeds een aantal jaren voorwerp van onderzoek. ${ }^{10}$ ) Met betrekking tot het jaar 1978 wijst een door ons on. dernomen onderzoek onder meer het volgende uit:

Van de vijftig grootste ondernemingen baseert nog bijna de helft (23) de officiële balans en resultatenrekening op de historische kostprijs (groep I). Een vrijwel even groot aantal (22) past in de officiële balans en resultatenrekening een meng. sel toe van historische kosten en actuele waarden (groep II). Slechts vijf ondernemingen baseren deze rekeningen volledig op actuele waarden (groep III).

\footnotetext{
4) Idem IV a ]-7, par. 34. Voor de vermogensbepaling worden lifo en jizerenvoorraadstelsel niet aanvaardbaar geacht (IV a 1.8, par. 42 en IV a 19 . par. 48 ).

5) Idem IV a 1.3 , par. 13

6) Idem IV a 1.10 , par. 50 en IV al 9 , par. 49

A. J. Bindenga, Informatie in de jaarrekening (1975), blz. 130; J. A. Burggraa[f, Arrest Ondernemingskamer houdt niet in dat accountant in beroepsuitoefening is tekortgeschoten (Het Financieele Dagblad van 13 oktober 1978).

-) De Accountant van oktober 1979 , blz. 74

y) J. W. Schoonderbeek, Regelgeving voor de jaarrekening, aard en werkwijze (De Naamlooze Vennootschap van januari/fe bruari 1979).

i) Zie hierover verder De ontwikkeling van het winstbegrip, bla. 77 e.y. Het hierna te bespreken onderzoek over 1978 is ver richt in samenwerking met $\mathrm{R}$. M. Vijn.
} 
Van groep $I$ is er slechts één onderneming (Hagemeyer), die ook in de toelichting of elders in het jaarverslag geen enkel element van actuele waarden vermeldt. De meeste ondernemingen (15) verstrekken als aanvullend gegeven de actuele waarde van een of meer categorieën vaste activa, of een min of meer ruwe be. nadering daarvan; meestal geven ze slechts de verzekerde waarde. Een zevental ondernemingen vermeldt als aanvullend gegeven de winst en meestal ook het vermogen op actuele waarde-basis. Bij vier ondernemingen wordt (bovendien) de te royale winstberekening volgens de historische kostprijs gecorrigeerd bij de winstverdeling. Dit geschiedt door in verband met de prijsstijging een deel van de berekende winst bij voorrang in te houden ten gunste van een reserve ter ver. vanging van de vaste activa.

Opvallend is dat de winstberekeningen op basis van de historische kostprijs meestal een belangrijk hogere uitkomst geven dan de winstbepaling op actuele waarde basis. Zo berekent Akzo in zijn officiële resultatenrekening een winst van f $49 \mathrm{mln}$; maar de aanvullende opstelling toont een verlies van $f 31 \mathrm{mln}$ (basis zijn de historische kosten resp. actuele waarden; beide bedragen zijn vóór aftrek van buitengewone baten en lasten ad $f 25 \mathrm{mln}$ verlies). Uit haar aanvullende be rekening trekt Akzo de consequentie, dat bij de winstbestemming alle winst wordt gereserveerd.

Bij Nutricia daarentegen is het verschil tussen de officiële en de aanvullende winstberekening veel geringer ( $f, 5 \mathrm{mln}$ resp. f $4,2 \mathrm{mln}$ ). De oorzaak hiervan is dat in de aanvullende actuele waarde-berekening bij deze onderneming de toe. voeging aan de rekening Herwaardering mede wordt bepaald op basis van de financiële structuur. Dat wil zeggen dat een deel van de waardestijging der materiële activa tot de winst wordt gerekend, en wel voor dat gedeelte van deze activa dat met vreemd vermogen wordt gefinancierd. Toepassing van deze financie ringscorrectie kan inderdaad een sterk winstverhogend effect hebben. Uit het getallenvoorbeeld dat ter toelichting aan dit artikel als bijlage is toegevoegd, blijkt dat de winst door deze correctie in een bepaald jaar zelfs hoger kan uitvallen dan die volgens de historische kostprijs ${ }^{11}$ ). De aandacht verdient voorts dat bij Nutricia - evenals bij Akzo - in de winstbestemming allereerst een bedrag wordt ingehouden ten bate van de vervangingsreserve; daar de aanvullende berekening slechts f $0,3 \mathrm{mln}$ lager uitvalt dan de officiële, zou men een dotatie aan deze reserve mogen verwachten van slechts dit bedrag; in feite is deze dotatie echter $f 2,5 \mathrm{mln}$. Ligt aan de berekening van dit laatste bedrag een derde winstbepalingsmethode ten grondslag, b.v. de klassieke vervangingswaardemethode?

Binnen groep II, die een mengsel toepast van historische kosten en actuele waarden, doet zich een reeks van varianten voor. Wij volstaan met enkele voorbeel den:

- KBB: De afschrijving op basis van de historische kosten wordt aangevuld tot de „bedrijfseconomische afschrijving”. Aangenomen dat dit de actuele waarde.afschrijving is berust de winstbepaling dus goeddeels op de grondslag van de actuele waarde. Het vermogen wordt evenwel niet gecorrigeerd (afgezien van de dotatie aan de vervangingsreserve). Deze methode is dus inconsistent.

\footnotetext{
11) Na volledige realisatie van de waardestijging der materiële activa zal uiteraard bljiken dat over de gehele periode van rea lisatic gerekend de winst volgens de historische kostprijsmethode lager uitvalt dan die volgens deze actuele waardemethode. Bij deze laatste wordt immers uit de totale vermogensaanwas een correctie van het eigen vermogen afgezonderd; slechts het restant wordt als winst beschouwd.
} 
De rentabiliteit kan slechts worden bepaald door deling van bedragen die op een verschillende basis zijn berekend.

- Hoogovens: Voor zover het de vlottende activa betreft wordt de winst berekend op een actuele waarde-grondslag en wel volgens het lifostelsel; ook het vermogen wordt op die grondslag bepaald. Maar voor de vaste activa wordt in de winst- en vermogensbepaling de historische kostprijs aangehouden. Gevreesd moet worden dat juist voor die activa deze grondslag ernstig tekort schiet.

- Océ van der Grinten: De winst wordt berekend op actuele waarde-basis voor zover het de vaste activa betreft; ditzelfde is met het vermogen het geval. Het dualisme van deze methode is spiegelbeeldig aan dat van de Hoogovens.

- Elsevier/NDU: Hier wordt dezelfde methode toegepast als bij Océ van der Grinten. Twee aspecten verdienen echter bijzondere aandacht:

a) De officiële winstberekening wordt aangevuld met een berekening van de „Pro forma vermogensgroei in reële koopkracht". De uitkomst van deze nacalculatie is naar wij menen gelijk aan de winst volgens de geldwaarde. correctiemethode.

b) In de officiële winstberekening wordt een financieringscorrectie toegepast. Uitgangspunt hiervoor is de normatieve verhouding tussen het „garantie. vermogen" en het ,rentedragend vreemd vermogen inclusief voorzienin. gen" van $50: 50 .{ }^{2}$ )

Van de vijf ondernemingen die groep III vormen vullen twee hun officiële be rekening aan met winst en vermogensbepaling op historische-kostenbasis. Elk de zer ondernemingen voegt aan de rekening Herwaardering de waardestijging der materiële activa toe, verminderd met de daarop drukkende belasting. Dit laatste is doorgaans ook het geval bij de ondernemingen uit de andere groepen, voor zover zij de vervangingswaardemethode toepassen. De consequentie daarvan is dat het eigen vermogen in tijden van prijsstijging slechts toeneemt met een deel (meestal ongeveer de helft) van genoemde waardestijging. Aan het instandhoudingspostulaat van de klassieke vervangingswaardeleer, met name de kapitaal. handhaving, wordt aldus in belangrijke mate niet meer voldaan. De vraag rijst, welke andere handhavingsdoelstelling dan - zij het stilzwijgend - aan de jaarrekening van de desbetreffende onderneming ten grondslag ligt. Dit zou bijv. kunnen zijn de specifieke koopkrachthandhaving van het eigen vermogen. Deze doelstel. ling bereikt men door in de plaats van de klassieke Herwaardering een eigen-vermogenscorrectie te stellen ter grootte (procentueel) van de specifieke prijsstijging; dit is de prijsstijging van de goederen die voor de onderneming relevant zijn.

Indien men de rekening Herwaardering crediteert voor de helft van de waar. destijging der materiële activa, realiseert men de specifieke koopkrachthandhaving van het eigen vermogen, mits het belastingpercentage $50 \%$ is en het eigen vermogen de helft bedraagt van het materiële actief. Bij Philips was dit de afge lopen jaren grosso modo het geval, mits men in plaats van eigen vermogen groepsvermogen neemt. Maar bijv. bij Akzo was aan deze laatste voorwaarde niet voldaan; bij dit concern werd dientengevolge een groter deel aan Herwaardering

\footnotetext{
12) In zijn reeds genoemde publikatie over informate in de jaarrekening bepleit Bindenga, tot voor kort lid van de raad van bestuur van Elsevier/NDU, in de bepaling van de resultaten onder andere en voor zover nodig een voorziening te treffen voor de "algemene koopkrachthandhaving”. Ook wil hij bij de resultatenbepaling rekening houden met de verhouding tussen eigen en vreemd vermogen en wel met die, welke "gewenst wordt en mogelijk is" (t.a.p. blz. 229 e.v.).
} 
toegevoegd dan nodig was voor de specifieke koopkrachthandhaving van het ei. gen vermogen. Van welk instandhoudingspostulaat wordt bij Akzo (en anderen!) dan wel uitgegaan, indien men noch de klassieke vervangingswaardemethode, noch de moderne variant ervan (met financieringscorrectie) toepast?

\section{Slotbeschouwing en conclusies}

1. Uit het bovenstaande concluderen wij dat in ons land in de gepubliceerde jaar. rekening van de vijftig grootste ondernemingen een verwarrende veelheid van winst en vermogensbepalingsmethoden wordt toegepast. Door combinatie van de diverse mogelijkheden met betrekking tot de officiële balans en resultatenrekening met de diverse mogelijkheden van aanvulling van deze rekeningen kan men bij deze groep van ondernemingen gemakkelijk tot enige tientallen varianten komen.

2. De historische-kostprijsmethode blijkt nog veel te worden toegepast, vaak zonder aanvulling van wezenlijke betekenis.

3. De praktijk wint veld dat men in één jaarrekening de winst en eventueel ook het vermogen bepaalt volgens twee methoden. Dit is in overeenstemming met de ontwikkeling in de Verenigde Staten en Engeland en evenzeer met de nieuwste richtlijnen van het TO hieromtrent. Het grote bezwaar ervan is dat de lezer van het jaarverslag omtrent de grootte van resultaat en vermogen twee uitkomsten voorgelegd krijgt, die veelal sterk uiteenlopen en waar. van het jaarverslag niet duidelijk maakt, hoe deze uitkomsten zich tot elkaar verhouden. Van ondubbelzinnigheid der verstrekte informatie kan aldus moeilijk worden gesproken.

4. Winst- en vermogensbepaling deels op basis van historische kosten, deels op actuele waarde-basis, is een betrekkelijk wijd verbreide praktijk. Deze tweeslachtigheid mist elke bedrijfseconomische ratio.

5. De toelichting en de motivering van de gebezigde winst- en vermogensbepalingsmethode zijn vaak onvoldoende. Zo wordt veelal niet of onvolledig meegedeeld, hoe de actuele waarde (indien toegepast) wordt bepaald, of daarbij rekening is gehouden met de ontwikkeling van de techniek, en welk deel van de waardestijging der materiële activa naar Herwaardering resp. latente belastingschuld gaat. Een motivering van laatstgenoemde verdeling met behulp van de handhavingsdoelstelling van de onderneming ontbreekt doorgaans.

6. De winst-en vermogensbepaling mag in de verschillende ondernemingen op velerlei wijze geschieden, een verklaring van de accountant in deze zin dat de jaarrekening een getrouw beeld geeft van grootte en samenstelling van vermogen en resultaat, ontbreekt nimmer. Dit is ook het geval in de jaarverslagen waarin winst en vermogen op twee (of drie) verschillende manieren worden berekend. Meestal heeft de accountantsverklaring betrekking op beide berekeningen. ${ }^{13}$ ) Kan de modale lezer van het jaarverslag in zulke gevallen doorgronden wat de draagwijdte is van de zinsnede ,een getrouw beeld"?

7. De nieuwe richtlijnen van het TO met betrekking tot de grondslagen van de winst- en vermogensbepaling betekenen ongetwijfeld een belangrijke stap voorwaarts, die ongetwijfeld veler verwachtingen zal hebben overtroffen.

\footnotetext{
13) Koninklijke Olie heeft voor de aanvullende winst en vermogensopstelling een afzonderlijke accountantsverklaring. Onder andere bij Unilever valt de aanvullende opstelling formeel buiten de jaarrekening.
} 
Maar de bezwaren die kleven aan de huidige praktijk in ons land en die hierboven werden uiteengezet, worden er slechts ten dele door ondervangen. Zo blijven er meerdere actuele waarde-methoden toegestaan, waaronder de ge. brekkige ijzerenvoorraad. en lifomethode; de geldwaardecorrectiemethode wordt daarentegen niet aanvaard. Bovendien kan voor de officiële balans en resultatenrekening de historische-kostprijsmethode worden gehandhaafd. Meer dan één methode in één jaarverslag wordt niet alleen toegestaan, het wordt zelfs verlangd. Ook de vaak gebrekkige wijze van toelichting en moti vering (zie boven) wordt naar wij vrezen onvoldoende verholpen; met name betreft dit het gehanteerde instandhoudingspostulaat.

Tenslotte vormt een probleem, of door de normering van het TO de afstand ten opzichte van het buitenland niet kan worden vergroot. De reeds bestaan. de moeilijkheden van de internationaal opererende ondernemingen zouden daardoor nog toenemen. ${ }^{14}$ )

BIJLAGE

\section{Getallenvoorbeeld}

Balans per 1.1.79*

\begin{tabular}{lc|ll}
\hline Duurz. prod.middel** & 40 & Eigen vermogen & 35 \\
Goederen 30 st. à 1,- & 30 & Vreemd vermogen & 65 \\
Monetaire activa & 30 & & \\
& $\overline{100}$ & & 100
\end{tabular}

* De balansverhoudingen zijn gebaseerd op de CBS statistiek beurs-n.v.'s 1977.

* Levensduur 10 jaar.

Transacties: $1 / 5$ Inkoop 80 à $f 1,05=84,-$

$$
1 / 8 \text { Verkoop } 75 \text { à } f 1,15=86,25
$$

Verloop vervangingsprijs van de goederen: januari/maart $f$ 1,-

$\begin{array}{ll}\text { april/juni } & f 1,05 \\ \text { juli/sept. } & f 1,08 \\ \text { oktober/dec. } & f 1,10\end{array}$

Het dpm blijkt op 31.12.79f 44,- te kosten.

Het algemeen prijsindexcijfer stijgt van 100 per 1.1 .79 tot 112 per 31.12.79.

\footnotetext{
14) Deze moeilijkheden worden uiteengezet door de president van de Koninklijke Olie, D. de Bruyne, in zijn rede van 14 ok. tober 1979: Insermational harmonization of accounting and disclosure standards.
} 
Winstbepaling volgens vijf methoden:

\begin{tabular}{|c|c|c|c|c|c|}
\hline & I & II & III & IV & $\mathrm{V}$ \\
\hline Omzet & 86,25 & 86,25 & 86,25 & 86,25 & 86,25 \\
\hline Kosten van de omzet & $\left\{\begin{array}{l}30,- \\
47,25\end{array}\right.$ & 78,75 & $81,-$ & $81,-$ & $81,-$ \\
\hline $\begin{array}{l}\text { Winst op goederen } \\
\text { excl. specul. res. } \\
\text { Speculatieresultaat }\end{array}$ & $9,-$ & 7,50 & $\begin{array}{l}5,25 \\
2,50\end{array}$ & $\begin{array}{l}5,25 \\
2,50\end{array}$ & $\begin{array}{l}5,25 \\
2,50\end{array}$ \\
\hline $\begin{array}{l}\text { Winst op goederen } \\
\text { incl. specul. res. } \\
\text { Herwaardering minus correctie }\end{array}$ & $9,-$ & 7,50 & 7,75 & 7,75 & 7,75 \\
\hline $\begin{array}{l}\text { eigen vermogen } \\
\text { Afschrijving }\end{array}$ & $4,-$ & $4,-$ & 4,40 & $\begin{array}{l}2,80 \\
4,40\end{array}$ & $\begin{array}{l}3,50 \\
4,40\end{array}$ \\
\hline Nettowinst & $5,-$ & 3,50 & 3,35 & 6,15 & 6,85 \\
\hline
\end{tabular}

I $=$ Minimumwaarderingsregel

II = IJzerenvoorraadmethode

III = Klassieke vervangingswaardemethode

IV = Geldwaardecorrectiemethode

$\mathrm{V}$ = Vervangingswaardemethode met financieringscorrectie (specifieke koop. krachthandhaving).

N.B. IV en $V$ zijn vóór aftrek eventuele voorziening voor het ongerealiseerde deel van de waardestijging der materiële activa. 